\title{
Multimodal response to copper binding in superoxide dismutase dynamics
}

\author{
Marta Bonaccorsi ${ }^{\mathrm{a}}$, Michael J. Knight ${ }^{\mathrm{a}}$, Tanguy Le Marchand ${ }^{\mathrm{a}}$, Hugh R. W. Dannatt ${ }^{\mathrm{a}}$, Tobias \\ Schubeis $^{\mathrm{a}}$, Loïc Salmon ${ }^{\mathrm{a}}$, Isabella C. Felli ${ }^{\mathrm{b}}$, Lyndon Emsley ${ }^{\mathrm{c} *}$, Roberta Pierattelli ${ }^{\mathrm{b} *}$ and Gui- \\ do Pintacuda ${ }^{\mathrm{a} *}$
}

a Centre de RMN à Très Hauts Champs, FRE 2034 (CNRS / Université Claude Bernard Lyon 1 / Ecole Normale Supérieure de Lyon), University of Lyon - 69100 Villeurbanne (France)

b Department of Chemistry "Ugo Schiff" and CERM, University of Florence - 50019 Sesto Fiorentino (Italy)

${ }^{\mathrm{c}}$ Laboratory of Magnetic Resonance, Institute of Chemical Sciences and Engineering, Ecole Polytechnique Fédérale de Lausanne (EPFL) - CH-1015 Lausanne (Switzerland)

\begin{abstract}
Copper/zinc superoxide dismutase (SOD) is a homodimeric metalloenzyme which has been extensively studied as a benchmark for structure-function relationships in proteins, in particular because of its implication in the familial form of the neurodegenerative disease amyotrophic lateral sclerosis. Here, we investigate microcrystalline preparations of two differently metallated forms of SOD, namely the fully mature functional $\mathrm{Cu}^{\mathrm{I}}$,Zn state and the E,Zn-SOD state in which the $\mathrm{Cu}$ site is empty. By using solid-state NMR with fast magic-angle spinning (MAS) at high magnetic fields ( ${ }^{1} \mathrm{H}$ Larmor frequency of 800-1000 $\mathrm{MHz}$ ), we quantify motions spanning a dynamic range from ns to ms. We determine that metal ion uptake does not act as a rigidification element but as a switch redistributing motional processes on different timescales, with coupling of the dynamics of histidine sidechains and those of remote key backbone elements of the protein.
\end{abstract}

\section{Introduction}

Metal ions have a key role in the cell machinery as cofactors of almost one third of all the known proteins. ${ }^{1}$ They perform a variety of functions such as catalysis, electron transfer and oxygen storage. ${ }^{2}$ Often, metal ion binding also has a structural effect, modulating the stability and the folding pathways of metalloproteins. It is commonly thought that metal binding promotes a rigidification of the protein scaffold due to changes in side chain structure and dynamics in the metal binding site upon metal uptake. $^{3-6}$ However, a number of intriguing exceptions to this paradigm have been reported, ${ }^{7-11}$ suggesting that the repercussions of metal binding on stability, oligomerization and catalytic activity cannot be reconciled simply in terms of an overall reduction in flexibility. A more complete description of the modulation of motions on different timescales (from fluctuations at amino acid level to collective motions involving larger structural elements) ${ }^{12}$ is indeed required to disentangle all the effects.

One of the unique features of nuclear magnetic resonance (NMR) toward this goal is its capability to probe internal molecular motions at atomic resolution over a broad dynamic range in physiological environments. The continuous development of solid-state NMR has allowed to extend these investigations to complex targets of different aggregation states, to insoluble oligomers, sediments, and proteoliposomes. ${ }^{13-15}$ Solid-state NMR additionally provides the intriguing possibility to probe dynamical parameters of soluble proteins inside hydrated crystals or microcrystals ${ }^{16-21}$ and can therefore expand solution NMR methods. Pioneering studies have shown that the local flexibility of backbone and side-chains in crystals is reminiscent, if not identical, to that occurring in solution, ${ }^{22,23}$ and that relaxation parameters under MAS can even reveal residual collective motions that are associated with large-amplitude conformational changes in solution. ${ }^{24,25}$ In addition, crystal contacts abolish the overall tumbling of the molecules, which dominates spin relaxation in solution, and allow observation of motions over an expanded time window, necessary to obtain a comprehensive description of the functional dynamics of the proteins. $14,26,27$

Here, we use state-of-the-art solid-state NMR to characterize motions in a metalloenzyme, human copper/zinc superoxide dismutase (SOD), and to uncover the links between internal dynamics over various timescales and metal ions coordination, which are central to the processes of catalytic efficiency, maturation and stability of the dimeric enzyme. 
SOD is a well-known metalloenzyme found in almost all eukaryotic cells and in a few prokaryotes, which catalyzes the dismutation of the superoxide radical to hydrogen peroxide and oxygen. This system has been widely studied over the years as a benchmark for structure-function relationships in metalloproteins. ${ }^{28,29}$ Human $\mathrm{Cu}, \mathrm{Zn}-\mathrm{SOD}$ is a remarkably stable protein, ${ }^{30}$ with two identical subunits (153 aa) featuring a very well conserved $\beta$-barrel structure composed of eight antiparallel $\beta$ strands (Figure 1a), held together by hydrophobic interactions involving mainly two loops (namely 4 and 6). ${ }^{31,32}$ Each subunit contains in the active site a $\mathrm{Zn}^{\mathrm{II}}$ ion, buried inside the protein (Figure 1b) and known to have a primarily structural role. A solvent-accessible $\mathrm{Cu}$ ion (with oxidation state I or II during dismutation reaction) lies at the bottom of a wide active channel (Figure 1c) which is involved in efficiently driving the superoxide to the active site. Dismutation occurs with high catalytic efficiency, which is diffusion limited $\left.\left(k_{\mathrm{CAT}} \sim 10^{9} \mathrm{M}^{-1} \mathrm{~s}^{-1}\right)\right)^{31,33,34}$ The coordination of copper and zinc in the active site is mainly mediated by the side chains of histidine residues (Figure $1 \mathrm{~d}$ ): $\mathrm{Cu}^{\mathrm{I}}$ is coordinated by His 46 (strand $\beta_{4}$ ), His 48 (strand $\beta_{4}$ ) and His 120 (strand $\beta_{7}$ ). $\mathrm{Zn}^{\mathrm{II}}$ is coordinated by His 63 , His 71 , His 80 and Asp 83, all located in loop 4. In addition, His 63 is responsible of coordinating copper when it adopts an oxidation state II. (a)

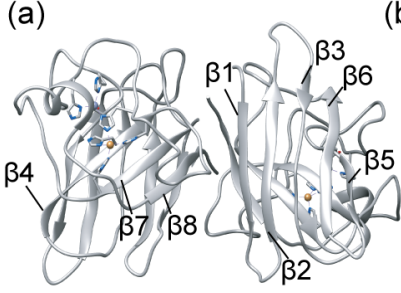

(c)

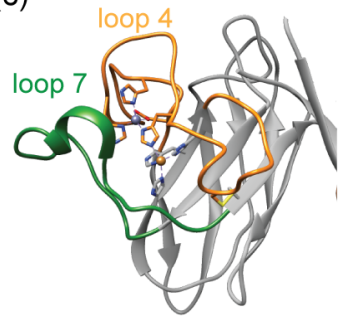

(b)

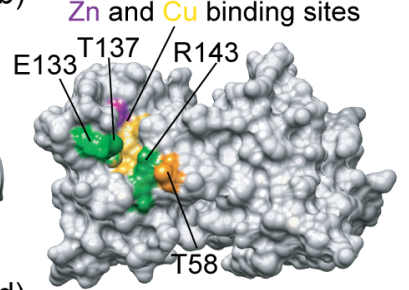

(d)

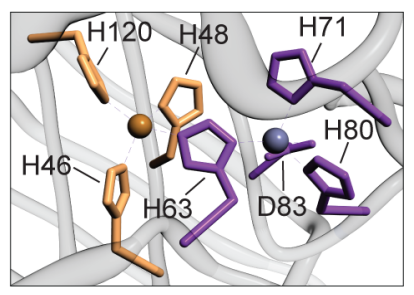

Figure 1. (a) Structure of the homodimer of $\mathrm{Cu}, \mathrm{Zn}-\mathrm{SOD}$ (PDB code:ISOS). The $\mathrm{Cu}$ and $\mathrm{Zn}$ metal ions are represented by a gold and a blue sphere respectively. (b) Solvent excluded surface of $\mathrm{Cu}, \mathrm{Zn}-\mathrm{SOD}$, where the active channel is shown in orange ( $\mathrm{T}_{5} 8$ in loop 4) and green (E133, $\mathrm{T}_{137}, \mathrm{R}_{143}$ in loop 7). This has a role in attracting superoxide anions and guide them into the channel to the copper ion. The binding sites of $\mathrm{Cu}$ and $\mathrm{Zn}$ ions are shown in yellow and purple respectively. $\mathrm{Cu}$ is solvent accessible at the end of the active channel, while $\mathrm{Zn}$ shielded at the protein core. (c) Zoom of the structure in the region of the active channel. The residues involved in metal coordination are shown with sticks. Loops 4 and 7 are colored in orange and green respectively. The fully conserved disulfide bridge between $\mathrm{C}_{57}$ and $\mathrm{C}_{14} 6$ is shown as a yellow stick. (d) Structure of the active site. Side chains of the residues involved in the metal coordination are shown as sticks and the residue numbering is indicated. $\mathrm{Cu}$ - coordinating residues are colored in gold, Zn-coordinating residues are colored in purple.

Systematic comparative studies have been performed on different forms of SOD, carrying or lacking $\mathrm{Cu}$, by solution NMR. ${ }^{28,31,33,35-39}$ These studies have contributed a picture showing that $\mathrm{Cu}$ uptake induces rigidification of both the active site and of the backbone of the protein overall. Nevertheless, in all these studies the effect of $\mathrm{Cu}$ uptake could not be separated from the effect of punctual mutations, which were designed specifically to produce an (inactive) monomeric variant suitable for solution studies. Moreover, motional processes occurring on different timescales, such as slow conformational changes and fast fluctuations, could not be connected in a single frame of reference.

In the following, we show that the previous picture of $\mathrm{Cu}$ induced rigidification was incomplete, and that in fact $\mathrm{Cu}$-binding increases local dynamics on fast timescales and reduces dynamics on slower timescales. We do this through the observation of dynamical parameters by solid-state NMR on hydrated microcrystalline preparations that conserve the enzymatic activity (SI text and figure $\mathrm{S} 1$ ). We study here an intermediate that contains all the features of the dimeric mature form, differing only by the absence of $\mathrm{Cu}$ (E,Zn-SOD hereafter). The dynamics of this intermediate are compared with those of the mature $\mathrm{Cu}^{\mathrm{I}}-$ bound enzyme $(\mathrm{Cu}, \mathrm{Zn}-\mathrm{SOD})$. The structures of both forms have been determined, ${ }^{33,40-42}$ and no evident structural changes are induced in the protein backbone by the uptake of $\mathrm{Cu}$. Nonetheless, significant variations are observed in the backbone mobility of relevant regions of SOD. By virtue of the definition of the target systems, such variations are not associated with point mutation nor with dimerization, and are uniquely ascribed to the copper binding, clarifying the key determinants relating copper uptake, functional protein backbone and sidechain motions and dimer stability.

\section{Materials and Methods}

Sample preparation. The $\mathrm{C} 6 \mathrm{~A} / \mathrm{C}_{111} \mathrm{~S}$ thermostable mutant of SOD, $\mathrm{U}-\left[{ }^{2} \mathrm{H},{ }^{13} \mathrm{C},{ }^{15} \mathrm{~N}\right]$ labelled and completely reprotonated at exchangeable positions, was prepared as described previously. ${ }^{42}$ Selective metallation was achieved by treating the purified and back-exchanged protein sample with EDTA followed by dialysis, stoichiometric addition of $\mathrm{Zn}^{\mathrm{II}}$ as a $10 \mathrm{mM} \mathrm{ZnCl}$ solution, followed, in the case the $\mathrm{Cu}, \mathrm{Zn}-\mathrm{SOD}$ sample, by slow titration with a 10 $\mathrm{mM}$ solution of $\mathrm{CuCl}_{2}$. The sample was then concentrated to $20 \mathrm{mg} / \mathrm{ml}$ and 1.5 molar equivalents of iso-ascorbic acid under nitrogen atmosphere were added to obtain the $\mathrm{Cu}^{\mathrm{I}}$ form. Both samples were then crystallized using the same procedure and timing by the sitting drop method, yielding microcrystals comparable in shape and dimension at visual inspection, and packed into $1.3 \mathrm{~mm}$ rotors by centrifugation. The $\mathrm{Cu}, \mathrm{Zn}$-SOD sample was determined to be functionally active. Details of all these procedures are described in the Supporting Information.

NMR spectroscopy. NMR spectra were carried out on a 23.5 $\mathrm{T}\left({ }^{1} \mathrm{H}\right.$ Larmor frequency $\left.1000 \mathrm{MHz}\right)$ and an $18.8 \mathrm{~T}$ 
(8oo MHz) narrow-bore Bruker Avance III spectrometers, with $60 \mathrm{kHz}$ MAS and a sample temperature of $27^{\circ} \mathrm{C}$. A proton-detected $3 \mathrm{D}(\mathrm{H}) \mathrm{CNH}$ experiment was employed to resolve resonances from histidine sidechains in three dimensions and correlate side-chain $\mathrm{NH}$ protons with sidechain heavy atoms. All site-specific ${ }^{15} \mathrm{~N}$ relaxation measurements for backbone and histidine sidechains were performed with the pulse sequences reported in ${ }^{43}$. A full description of the NMR experiments is provided in the Supporting Information.

\section{Results}

Histidine side-chain structure. The metal ion coordination pattern in the active site is readily accessible to NMR through ${ }^{15} \mathrm{~N}-{ }^{1} \mathrm{H}$ cross-polarization-based $2 \mathrm{D}$ spectra, $\mathrm{CP}-$ (H) $\mathrm{NH}$, which contain resonances from $\mathrm{HN}$ pairs in $\delta$ and/or $\varepsilon$ positions of the imidazole groups of histidines. Such spectra were acquired for microcrystalline preparations of the two metallated forms of SOD and are shown in Figure 2a. Their site-specific assignment, performed using ${ }^{1} \mathrm{H}$-detected triple-resonance $3 \mathrm{D}$ experiments, is detailed in the SI text. In both forms, a single correlation peak was observed for each histidine sidechain in the active site, associated to a singly protonated form. In contrast, two correlations were observed for His43, indicating a doubly protonated form for this non-coordinating sidechain at the $\mathrm{pH}$ used for crystallization. The spectra of the two molecules are very similar, with ${ }^{15} \mathrm{~N}$ chemical shift perturbation upon copper binding smaller than $1.5 \mathrm{ppm}$. A noticeable difference is represented by the signal of His $120 \mathrm{NH} \delta_{1}$, which is absent in E,Zn-SOD, while it appears in the case of $\mathrm{Cu}, \mathrm{Zn}-\mathrm{SOD}$. These first observations indicate an overall conservation of structure, with the conservation of the tautomeric state of each histidine, but also suggest different dynamics between the two forms, with higher flexibility of His 120 , and consequent inefficient dipolar transfer, in the absence of $\mathrm{Cu}$.

Histidine side-chain dynamics. Interconversion between structurally similar states (separated by low energy barriers) occurs over a broad ps to $\mu$ s timescale, and nuclear spin relaxation parameters determined by MAS-NMR are informative of such motions. ${ }^{16,44-46}$ Here, the ${ }^{15} \mathrm{~N}-{ }^{1} \mathrm{H}$ correlation spectra provide a window for the direct measurement of such parameters at the catalytic center with atomic resolution. A set of ${ }^{15} \mathrm{~N} \mathrm{R}_{1}$ and $\mathrm{R}_{1 p}$ relaxation rates was measured for all the observed His side-chain signals, in both $\mathrm{Cu}, \mathrm{Zn}-\mathrm{SOD}$ and E,Zn-SOD. These parameters monitor differences in dynamics between metallation states covering the aforementioned time window, specifically from ps-ns $\left({ }^{15} \mathrm{~N} \mathrm{R}_{1}\right)$ to ns- $\mu s\left({ }^{15} \mathrm{~N} \mathrm{R}_{1 p}\right)$ processes, respectively (SI text and figure $\mathrm{S}_{2}, \mathrm{~S}_{3}$ ). The relaxation rates measured for the two forms are compared in Figure $2 \mathrm{~b}$ and listed in Table $\mathrm{S}_{1}$. Longitudinal relaxation rates $\left({ }^{15} \mathrm{~N}\right.$ $R_{1}$ ) are very well conserved between the two forms, with noticeable difference for the ${ }^{15} \mathrm{~N}_{2}$ of His 63 , showing considerably larger $R_{1}$ in the absence of $\mathrm{Cu}$. The residues in the $\mathrm{Cu}$ pocket (His 46 , His 48 and His 63) showed increased $R_{1 \rho}$ in E,Zn-SOD. Conversely, His 43, which is not exposed to the active site, showed conserved $R_{1}$ and $R_{1 p}$ rates between metallation states.

In addition, we explored even slower conformational dynamics ( $\mu \mathrm{s}-\mathrm{ms}$ ) by measuring ${ }^{15} \mathrm{~N} \mathrm{R}_{1 p}$ at variable spin-lock field, the commonly named relaxation dispersion (RD) experiment. The high magnetic field strengths and the high MAS rates used here, together with proton dilution obtained in perdeuterated samples, reduce the coherent effect on the measured relaxation rates which are therefore dependent on dynamic processes only. ${ }^{18,45} \mathrm{~A}$ sloped profile in the relaxation dispersion is the signature of the presence of exchange between states with different chemical shifts on a $\mu \mathrm{s}-\mathrm{ms}$ timescale which translate into the existence of structural fluctuations. ${ }^{15} \mathrm{~N} \mathrm{R}_{1 \rho}$ relaxation dispersion profiles were measured for the His-sidechains of both SOD samples (Figure $2 \mathrm{c}-\mathrm{d}$ ). While a flat dependence of $R_{1 \rho}$ with respect to the spin lock field was observed for most of the histidine side-chains, a large dispersion was observed for His $6_{3} \mathrm{Ne}_{2}$ in the absence of $\mathrm{Cu}$. This spinlock dependence is abolished upon $\mathrm{Cu}$ binding.

Protein backbone structure. The observations above can be complemented by recording the analogous experiments on the ${ }^{1} \mathrm{H},{ }^{15} \mathrm{~N}$ pairs of the backbone amide groups, extending the investigation from the metal binding core to the whole protein scaffold. Fingerprint ${ }^{1} \mathrm{H},{ }^{15} \mathrm{~N}$ dipolar correlation spectra $\mathrm{CP}-(\mathrm{H}) \mathrm{NH}$ acquired on both $\mathrm{Cu}, \mathrm{Zn}$ SOD and E,Zn-SOD are reported in Figure za. The two spectra are almost superimposable, evidencing backbone structure and crystal packing conservation in the two forms with the exception of small variations in chemical shifts for backbone $\mathrm{NH}$ pairs close to the $\mathrm{Cu}$ pocket. For both samples, a single set of resolved peaks was detected, indicating the absence of exchange processes with other substantially populated conformers on timescales slower than ms.
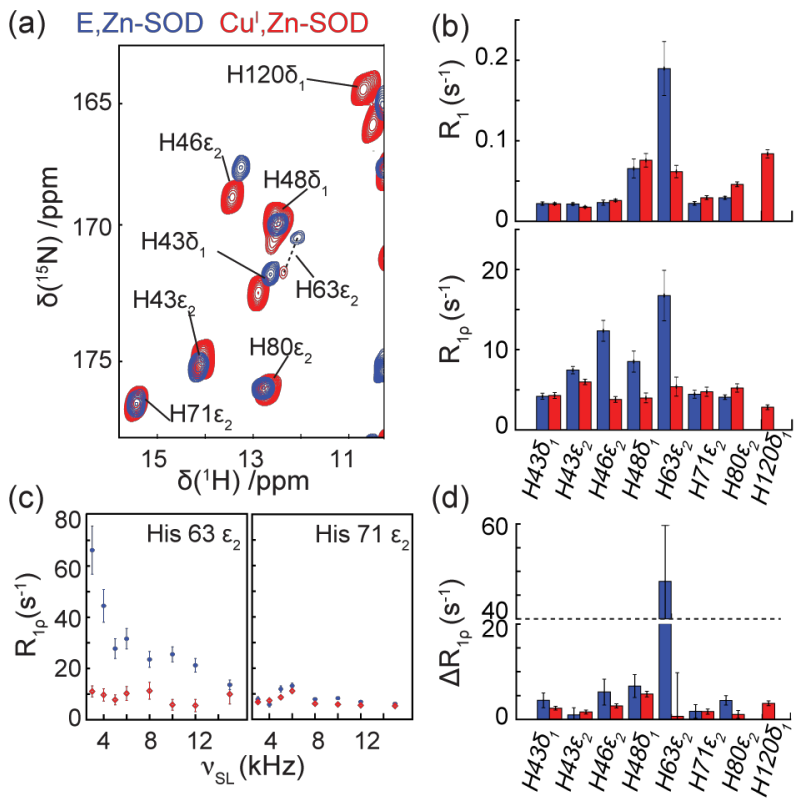

Figure 2. (a) Superposition of solid-state ${ }^{15} \mathrm{~N}-{ }^{1} \mathrm{H}$ CP-HSQC spectra of E,Zn-SOD (blue) and Cu,Zn-SOD (red) in the region of the side chains of histidine residues. The assignment 
of the different ${ }^{15} \mathrm{~N}$ in the imidazole rings is shown. (b) Summary of the results obtained for the ps-ns dynamics of the histidine side chains in E,Zn-SOD (blue) and $\mathrm{Cu}, \mathrm{Zn}$-SOD (red). Top: longitudinal ${ }^{15} \mathrm{~N}$ relaxation rates $\mathrm{R}_{1}$. Bottom: ${ }^{15} \mathrm{~N}$ relaxation rates $R_{1 \rho}$ with a spin-lock radiofrequency amplitude of $20 \mathrm{kHz}$. (c) ${ }^{15} \mathrm{~N} \mathrm{R}_{1 \rho}$ relaxation dispersion profiles observed in E,Zn-SOD (blue) and $\mathrm{Cu}, \mathrm{Zn}-\mathrm{SOD}$ (red) for the imidazole $\mathrm{N}_{2}$ of His 63 and His 71. (d) Imidazole ${ }^{15} \mathrm{~N} \Delta \mathrm{R}_{1 \rho}$ ( $\mu \mathrm{s}-$ ms dynamics) evaluated from relaxation dispersion profiles for E,Zn-SOD (blue) and Cu,Zn-SOD (red) .

(a)

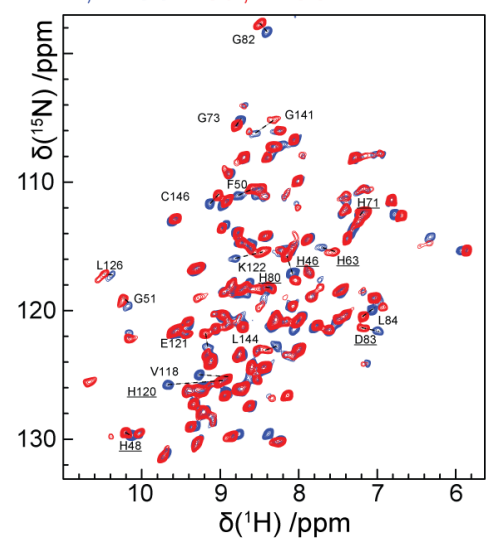

(b)

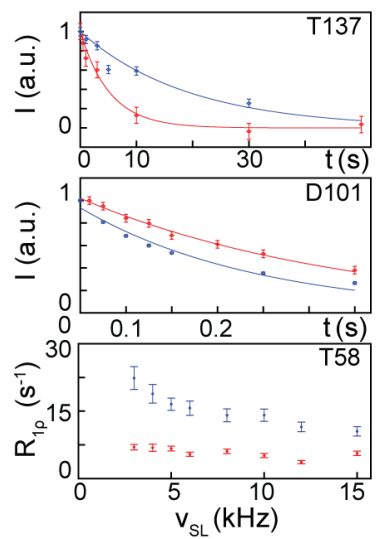

Protein backbone dynamics. As for the histidine sidechains, sets of ${ }^{15} \mathrm{~N} \mathrm{R}_{1}$ and $R_{1 \rho}$ rates as well as $R_{1 \rho}$ relaxation dispersion profiles were measured for $\sim \mathbf{1 4 0}$ amide groups along the protein backbone, in both $\mathrm{Cu}, \mathrm{Zn}-\mathrm{SOD}$ and E,Zn-SOD.

Representative ${ }^{15} \mathrm{~N} \mathrm{R}_{1}$ and $\mathrm{R}_{1}$ decays are displayed in Figure $3 \mathrm{~b}$. The values obtained for all the analyzed residues are displayed in Figure $3 c$ and listed in Table S1. While $\mathrm{R}_{1}$ relaxation rates are rather similar for the two forms for most of the backbone amide groups, three regions with globally larger

(c) $\beta 1 \quad \beta 2 \quad \beta 3 \quad \beta 4 \quad \beta 5 \quad \beta 6 \quad \beta 7 \quad \alpha 1 \quad \beta 8$
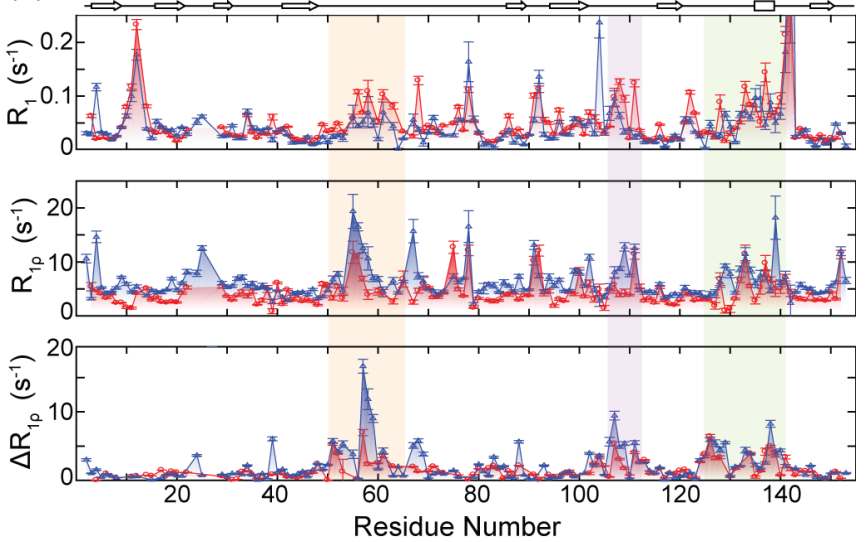

Figure 3. (a) Superposition of ${ }^{15} \mathrm{~N}-{ }^{1} \mathrm{H}$ CP-HSQC spectra of E,Zn-SOD (blue) and Cu,Zn-SOD (red), recorded at 1 GHz ${ }^{1} \mathrm{H}$ Larmor frequency and 6o kHz MAS. The assignment of the most shifted residues and of the residues exposed in the active site (underlined) is reported according to Knight et al. $(32,33)$. (b) Relaxation profiles of representative residues in E,Zn-SOD (blue) and $\mathrm{Cu}, \mathrm{Zn}$-SOD (red). Top: ${ }^{15} \mathrm{~N} \mathrm{R}$ experimental decay curves and fit curves of residue T137 (loop 7 , active channel). Middle: ${ }^{15} \mathrm{~N} \mathrm{R}_{1 \rho}$ experimental decay curves and fit curve of residue Dio1 (in $\beta$-strand). Bottom: ${ }^{15} \mathrm{~N}$ relaxation dispersion profiles of residue T58 (loop 4, active channel and close to dimer interface). (c) ${ }^{15} \mathrm{~N}$ backbone relaxation rates measured for E,Zn-SOD (blue triangles) and $\mathrm{Cu}, \mathrm{Zn}$-SOD (red circles). Top: longitudinal ${ }^{15} \mathrm{~N}$ relaxation rates $\mathrm{R}_{1}$ (ps-ns dynamics). Middle: spin-lattice ${ }^{15} \mathrm{~N}$ relaxation rates in the rotating frame $\mathrm{R}_{1 \rho}$ with a spin-lock RF amplitude of $20 \mathrm{kHz}$ (ns- $\mu$ s dynamics). Bottom: ${ }^{15} \mathrm{~N} \Delta \mathrm{R}_{1 \rho}$ ( $\mu \mathrm{s}-\mathrm{ms}$ dynamics) for E,ZnSOD (top, blue) and Cu,Zn-SOD (bottom, red). The secondary structure is indicated above the plots. Orange and green boxes highlight the residues located in loop 4 and 7 respectively, where noticeable differences between the two metallated states were revealed.

values in $\mathrm{Cu}, \mathrm{Zn}-\mathrm{SOD}$ than in $\mathrm{E}, \mathrm{Zn}-\mathrm{SOD}$ were observed: around the active channel in loops 4 (residues $56,58,61$ ) and 7 (residues 133,137,141,142), and in loop 6 (residues 107-111). These regions are highlighted in Figure $3 \mathrm{c}$ and visible in Figure $\mathrm{S}_{4}$, in which the values of the relaxation rates are projected

on the crystal structure of dimeric SOD. In these regions, metal binding clearly results in an increase of motions on fast timescales. In parallel, an overall decrease of ${ }^{15} \mathrm{~N}_{1 \rho}$ was observed for $\mathrm{Cu}, \mathrm{Zn}-\mathrm{SOD}$ with respect to E,Zn-SOD, indicating a reduction of motions in the intermediate timescales all along the sequence.

As for relaxation dispersion profiles (a representative example is shown in Figure $3 \mathrm{~b}$ ), backbone residues can be sorted into three categories (Figure $\mathrm{S}_{5}$ ). For a first set of residues the $\mathrm{RD}$-profiles are flat for both samples, with little or no dependence of $R_{1 \rho}$ with the spin lock field, indicating the absence of exchange. In a second set, the same profile is observed for both samples, showing chem- ical exchange unrelated to copper binding. Lastly, for a third set of residues $R_{1 \rho}$ values at low spin-lock field are increased in E,Zn-SOD translating into an increase of motion on $\mu \mathrm{s}-\mathrm{ms}$ timescales in the absence of copper. Intriguingly, for these residues the features of the dispersion profile (slope and plateau) mirror those observed for His 63 side-chain $\mathrm{N}_{2}$. Slow dynamics is assessed here qualitatively, without imposing any particular model of motion, by simply using $\Delta \mathrm{R}_{1 \rho}$, the difference of $\mathrm{R}_{1 \rho}$ between the lowest and the highest spin lock fields (Figure $3 \mathrm{c}$ ). The projection of $\Delta \mathrm{R}_{1 \rho}$ values onto the crystal structure of SOD (Figure $\mathrm{S}_{4}$ ) reveals that the portions of the loops with higher values and the major differences between the two metallated forms cluster in loops 4 (residues $51,53,57^{-}$ 59,67,68), 6 (residues 106-111) and 7 (residues 126-129,138) close to the metal binding site but also around the dimer interface.

\section{Discussion}


The structures of many differently metallated intermediates, with various permutations of post-translation metallations, have been solved by NMR and X-ray crystallography, elucidating the maturation pathway of SOD. ${ }_{28,35,36,47}$ It is known that, after protein expression, $\mathrm{Zn}$ is taken up first and induces folding of the protein. ${ }^{48}$ In particular, loop 7 , which is randomly oriented in the apo form, ${ }^{36,40}$ adopts a defined orientation in the presence of Zn. Additionally the copper binding site adopts a geometry suitable for coordination. ${ }^{49}$ The uptake of $\mathrm{Cu}$ occurs as the final step in maturation of SOD and, while not inducing sensible changes in the overall structure, ${ }^{38,47}$ it affects the flexibility and the stability of the enzyme. ${ }^{50}$ The effect of copper coordination on the dynamics of the enzyme has been investigated by solution NMR on a monomeric mutant, showing a rigidification of the protein backbone upon metal binding on the sub-ns and ms- $\mu \mathrm{s}$ timescales. ${ }^{33}$ Similarly, the crystal structure of a $\mathrm{Cu}$ depleted mutant showed that in the absence of copper the functional loops 4 and 7 are poorly resolved, likely due to dynamics..$^{51}$ Nevertheless, with this approach the effect of metal binding could not be disentangled from the effect of dimerization and of punctual mutations. More importantly, the effect of metal uptake and its implication in the functionality of the enzyme cannot be ascribed to a simple linear response..$^{52}$ Culik et al. recently expanded this in a multi-time scale analysis of dynamics, ${ }^{53}$ investigating both the presence of conformational exchange at slow timescale and fast dynamics with measured nuclear Overhauser effect. However, the focus of the study being the investigation of the maturation pathway, motions in the fully mature form were not characterized.

We show here that the function of SOD seems to require fine-tuned dynamics, and does it in an articulated way. $\mathrm{Cu}$ binding, investigated here in absence of any other structural modifications, is indeed responsible of modulation of internal dynamics on multiple timescale. Making use of the site-specific precision and high sensitivity of solid-state NMR investigation on a large window of timescales, a richer picture of the effects induced by $\mathrm{Cu}$ uptake could be obtained. More specifically, the data permit us to associate copper binding with several interconnected layers of dynamics, each linked to a specific aspect of activity or stability, as detailed below and sketched in Figure 4.
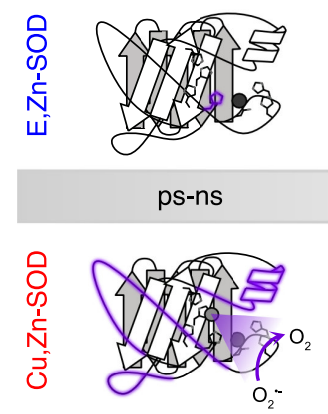

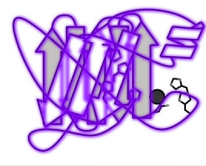

ns- $\mu s$

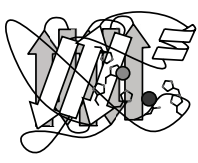

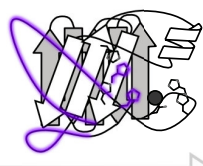
us-ms
Figure 4. Schematic view of the dynamical modes activated by $\mathrm{Cu}$ binding for the backbone and the metal-binding histidine residues of SOD over the three timescales investigated. For sake of clarity, SOD is represented by its monomer. Por- tions undergoing dynamics are highlighted by purple shadows. The superoxide diffusion pathway is symbolized by a gradient (lower, left panel).

$\mathrm{Cu}$ binds to a pre-structured rigid pocket. Absence of chemical shift changes in the ${ }^{1} \mathrm{H},{ }^{15} \mathrm{~N}$ correlations for the His side-chains indicates no change in the geometry of the metal binding pocket even upon copper binding. We can confirm that this pocket is extremely rigid on the fastest timescale sampled here (ps-ns), and its dynamical properties closely resemble those of the backbone residues in well-structured portions of the protein. With the notable exception of His 63 (see below), the presence of copper has little or no impact on such dynamics. The picture is dramatically different for slower timescales. In the ns- $\mu$ s window, the relaxation rates of side-chains reflect their degree of coordination, with smaller ${ }^{15} \mathrm{~N} \mathrm{R}_{1 p}$ for histidines coordinated to $\mathrm{Zn}$ in E,Zn-SOD and twice larger values for those facing the empty site. These values become uniformly small over the whole metal binding pocket in $\mathrm{Cu}, \mathrm{Zn}-\mathrm{SOD}$, which can be interpreted in terms of a further rigidification of the metal binding pocket on a slower timescale, consistently with previous work from Banci et al. ${ }^{31}$ by solution NMR. The fact that copper binding abrogates the protonation equilibria between cationic and neutral forms of the His imidazole rings within the metal binding pocket, ${ }^{54}$ may produce an additional reduction in ${ }^{15} \mathrm{~N} \mathrm{R}_{1 \rho}$ of His 46,48 and 120 in $\mathrm{Cu}, \mathrm{Zn}-\mathrm{SOD}$.

$\mathrm{Cu}$ binding activates fast dynamics in the active channel. Dynamics on the fastest timescale probed in this study were conserved for most of the backbone residues between the two forms. A local increase of longitudinal relaxation rates was however selectively observed for residues located around the active channel, indicating that $\mathrm{Cu}$ uptake acts as a "positive switch", triggering an increase of motions in the fast regime for this portion of the protein. This behavior is contrary to the general idea that metal binding is associated with a stiffening of the protein scaffold in metalloproteins. Interestingly, these results also counter the interpretation of previous solution NMR data which postulated a global rigidification of the backbone following $\mathrm{Cu}$ binding based on the change of the average $\mathrm{S}^{2}$ along the sequence. ${ }^{33}$ However, solid-state NMR is able to sample internal dynamics in the absence of overall molecular tumbling, allowing here for a clear separation of fast and slow timescale motions. The high catalytic efficiency in $\mathrm{Cu}, \mathrm{Zn}-\mathrm{SOD}\left(\mathrm{k}_{\mathrm{cat}} \sim 2 \times 10^{9} \mathrm{M}^{-1} \mathrm{~s}^{-155}\right)$ is connected not only to the correct conformation of the metal coordinating residues, but also to an efficient diffusion of the superoxide towards the active site. ${ }^{34}$ The fast motions detected here and activated by $\mathrm{Cu}$ binding match the estimated timescale for the diffusion of the superoxide anion through the active channel, suggesting a specific role in driving the superoxide ion. While the requirement of this kind of motions for SOD activity had been speculated on in the past, ${ }^{31}$ here the observation of increased fast motions compellingly connects to the presence of the catalytic ion.

$\mathrm{Cu}$ binding clogs intermediate dynamics overall. The effect of $\mathrm{Cu}$ binding is opposite if we move the observation win- 
dow to an intermediate timescale (ns- $\mu \mathrm{s})$. Here a uniform decrease of ${ }^{15} \mathrm{~N} \mathrm{R}_{1 \mathrm{p}}$ in both the $\mathrm{Cu}$-coordinating sidechains and in the backbone suggests a $\mathrm{Cu}$-driven "negative switch" of global motion. Such global motion could in principle be associated to a residual collective movement of the protein in the crystalline lattice, and evidence of such phenomena has recently been reported. ${ }^{17,18}$ The occurrence of this "rocking" motion cannot, however, account for the different ${ }^{15} \mathrm{~N} \mathrm{R} \mathrm{R}_{1 \rho}$ rates observed between the two SOD forms. Indeed, the properties of such motion are determined by the global protein shape (its tensor of inertia) and the lattice parameters (the crystal packing), ${ }^{45}$ which are both conserved in our two differently metallated samples. A more likely model which explains the differences between the two forms in our experimental data would involve segmental motions ${ }^{56}$ displacing the secondary structure elements with respect to each other. The inhibition of collective motions of the protein in this regime by $\mathrm{Cu}$ binding that we observe here is in line with the common framework of ligand-induced rigidification of metalloproteins communicated from the metal-binding site to distant regions.

$\mathrm{Cu}$ binding reduces slow dynamics at the dimer interface. The presence of large ${ }^{15} \mathrm{~N}$ relaxation dispersions is a signature of the occurrence of slow conformational exchanges between a ground state and thermally accessible states which are invisible both in X-ray data and in NMR spectra. These slow-timescale fluctuations affect residues close to the dimer interface in E,Zn-SOD, and are abrogated by copper binding. The absence of $\mathrm{Cu}$ therefore introduces the possibility of transient restructuring of the interface. With the regions concerned lying far from crystal contacts, ${ }^{18,57}$ these conformational exchange processes represent an intrinsic property of the molecule, and are likely to persist in solution. As dimerization is known to be a key feature for overall stability, the presence of transient states localized at the interface represents a mechanical explanation to interpret the large difference in the thermal stability measured in solution for E,Zn-SOD (melting temperature $\mathrm{T}_{\mathrm{m}}$ of $75^{\circ} \mathrm{C}$ ) and $\mathrm{Cu}, \mathrm{Zn}-\mathrm{SOD}\left(\mathrm{T}_{\mathrm{m}}\right.$ of $\left.92^{\circ} \mathrm{C}\right) .^{30,58}$ This may also provide a link to interpret the increased aggregation propensity observed in mutants designed to abrogate $\mathrm{Cu}$-binding. ${ }^{59,60}$ It is fascinating that such conformational transitions can be captured in a crystalline sample, in line with a growing body of evidence connecting slow dynamics in hydrated crystals with the corresponding phenomena in solution. ${ }^{19,20,61}$ It is also interesting to note that these conformational exchange processes present in E,Zn-SOD cannot be captured by solution NMR Carr-Purcell-Meiboom-Gill (CPMG) experiments, ${ }^{53}$ as their investigation requires high RF fields available only to solid-state NMR. ${ }^{15,62}$ These findings interestingly mirror the above analysis of fast dynamics $\left({ }^{15} \mathrm{~N}\right.$ $\mathrm{R}_{1}$ ). The very same regions (loops 4,6 and 7 ) undergoing increased ns motions in $\mathrm{Cu}, \mathrm{Zn}-\mathrm{SOD}$ experience an opposite effect on the $\mu \mathrm{s}-\mathrm{ms}$ timescales sampled by relaxation dispersion. This suggests $\mathrm{Cu}$ binding couples the structural stabilization of the dimer interface and the activation of motions in the superoxide diffusion channel.
Histidine side-chains couple metal binding to dynamics in remote protein regions. In the above picture of the effect of $\mathrm{Cu}$ binding on the histidine side-chains, outstanding is the behavior of $\mathrm{Zn}$-coordinating His 63, halfway between the $\mathrm{Zn}$ and $\mathrm{Cu}$ pockets, and His 120 . The side-chain of His 63 experiences abnormally large dynamics over all timescales in E,Zn-SOD. The presence of copper quenches most of these motions and levels its behavior to that of the other histidine residues. A similar behavior explains the appearance of a signal in the $\mathrm{HN}$ correlation from His 120 only in the presence of $\mathrm{Cu}$. Importantly, the consistency between the general features of the relaxation dispersion profiles for backbone amides in loops 4 and 7 and that of His63 $\mathrm{N}_{2}$ suggests a comparable timescale for the slow conformational exchanges occurring in the absence of $\mathrm{Cu}$, both in close proximity of the metal site and far from it. This observation highlights a pivotal role of His 63 in propagating the effect of $\mathrm{Cu}$-binding to spatially remote regions of the enzyme.

It is interesting to speculate on the mechanism of this transfer. Although not directly coordinated to $\mathrm{Cu}^{\mathrm{I}}$, His 63 faces the $\mathrm{Cu}$-binding pocket and it is sterically affected by the presence of the metal. Different from the three other His in the same pocket (46, 48 and 120), which all belong to $\beta$-strands, His 63 is located in the middle of loop 4 , which provides a broader conformational space compatible with larger changes of dynamics. Remarkably, the very same loop 4 anchors the metal center with the active channel and the dimer interface, so that dynamical changes for His 63 can easily be transferred away from the $\mathrm{Cu}^{\mathrm{I}}$ site. $^{63}$

\section{Conclusions}

In this work we have applied state-of-the-art solid-state NMR methods with fast MAS at the highest magnetic fields to disentangle the interplay between $\mathrm{Cu}$ uptake and the internal dynamics in human SOD. This was performed here regardless of any other post-translational events occurring in the maturation pathway (disulfide bond formation, dimerization, Zn-binding), by the comparison of two crystalline preparations differing uniquely for the presence of $\mathrm{Cu}^{\mathrm{I}}$ in the active site.

The measurement of solid-state NMR observables expands the window of timescales of motion accessible for atomic-scale investigation with respect to earlier analyses in solution, unraveling a purely dynamical, multimodal response of the skeleton of dimeric SOD upon binding of $\mathrm{Cu}^{\mathrm{I}}$ in its active site. In SOD, we find that metal ion uptake does not simply rigidify the enzyme but acts as a switch simultaneously both activating and deactivating motional processes on different timescales, with additionally coupling of the dynamics of histidine sidechains and those of remote key backbone elements of the protein. The multi-timescale dynamic mechanisms unveiled here for SOD are difficult to observe using other methods, and so they may be general and our observations could be pertinent for the description of metal ion binding in a variety of metalloproteins. 


\section{ASSOCIATED CONTENT}

\section{Supporting Information}

The Supporting Information contains a full description of the NMR experimental details, formulas and figures illustrating the sensitivity of the NMR to different timescales of motion, details on the activity assays, relaxation dispersion profiles as well as tables with site-specific relaxation data. This material is available free of charge on the ACS Publications website.

\section{AUTHOR INFORMATION}

\section{Corresponding Author}

* Email addresses: lyndon.emsley@epfl.ch, roberta.pierattelli@unifi.it, guido.pintacuda@ens-lyon.fr

\section{Author Contributions}

All authors have given approval to the final version of the manuscript.

\section{Funding Sources}

The work was co-funded by the European Research Council (ERC-2015-CoG GA 648974), the Agence Nationale de la Recherche (10-BLAN-713-01), Fondazione CR Firenze, Egide (programme Galilée $22397 \mathrm{RJ}$ ), the Università Italo-francese (programma Galileo 11/12), CNRS (IR-RMN FR3050) as well as by the EC-project iNext (infrastructure for NMR, EM, and Xrays for Translational Research, GA 653706).

\section{REFERENCES}

(1) Gray, H. B. Biological Inorganic Chemistry at the Beginning of the 21st Century. Proc Natl Acad Sci USA 2003, 100 (7), 3563-3568. https://doi.org/10.1073/pnas.073037810o.

(2) Bertini, I.; Sigel, A.; Sigel, H. Handbook on Metalloproteins; Marcel Dekker, N. Y.-B., Ed.; 2001. https://doi.org/https://doi.org/10.1023/A:1016317312012.

(3) Arnold, F. H.; Zhang, J. H. Metal-Mediated Protein Stabilization. Trends Biotechnol 1994, 12 (5), 189-192. https://doi.org/10.1016/o167-7799(94)90081-7. Babor, M.; Greenblatt, H. M.; Edelman, M.; Sobolev, V. Flexibility of Metal Binding Sites in Proteins on a Database Scale. Proteins Struct Funct Genet 2005, 59 (2), 221-230. https://doi.org/10.1002/prot.20431.

(5) Li, W.; Wang, J.; Zhang, J.; Wang, W. Molecular Simulations of Metal-Coupled Protein Folding. Curr Opin Struct Biol 2015, 30, 25-31. https://doi.org/10.1016/j.sbi.2014.11.oo6.

(6) Matsuo, T.; Kono, T.; Shobu, I.; Ishida, M.; Gonda, K.; Hirota, S. Global Structural Flexibility of Metalloproteins Regulates Reactivity of Transition Metal Ion in the Protein Core: An Experimental Study Using Thiol-Subtilisin as a Model Protein. Chem - A Eur J 2018, 24 (11), 2767-2775. https://doi.org/10.1002/chem.201705920.

(7) Deng, N. J.; Yan, L.; Singh, D.; Cieplak, P. Molecular Basis for the Cu2+ Binding-Induced Destabilization of B2Microglobulin Revealed by Molecular Dynamics Simulation. Biophys J 20o6, 90 (11), $3865-3879$. https://doi.org/10.1529/biophysj.105.064444.

(8) Sedlák, E.; Ziegler, L.; Kosman, D. J.; Wittung-Stafshede, P. In Vitro Unfolding of Yeast Multicopper Oxidase Fet3p Variants Reveals Unique Role of Each Metal Site. Proc Natl Acad Sci USA 2008, 105 (49), 19258-19263. https://doi.org/10.1073/pnas.0806431105.

(9) Morales, K. A.; Yang, Y.; Cole, T. R.; Igumenova, T. I. Dynamic Response of the $C_{2}$ Domain of Protein Kinase $C_{\alpha}$ to Ca2+ Binding. Biophys $J$ 2016, 111 (8), 1655-1667.
(10)

https://doi.org/10.1016/j.bpj.2016.09.0o8.

Ariöz, C.; Wittung-Stafshede, P. Folding of Copper Proteins: Role of the Metal? $Q$ Rev Biophys 2018, 51. https://doi.org/10.1017/Soo33583518000021.

Yadav, A.; Paul, S.; Venkatramani, R.; Ainavarapu, S. R. K. Differences in the Mechanical Unfolding Pathways of Apoand Copper-Bound Azurins. Sci Rep 2018, 8 (1), 1-13. https://doi.org/10.1038/s41598-018-19755-7.

Henzler-Wildman, K.; Kern, D. Dynamic Personalities of Proteins. Nature 2007, $450 \quad$ (7172), $\quad 964-972$. https://doi.org/10.1038/natureo6522.

Lewandowski, J. R. Advances in Solid-State Relaxation Methodology for Probing Site-Specific Protein Dynamics. Acc Chem Res 2013, 46 (9), 2018-2027. https://doi.org/10.1021/ar300334g.

Lewandowski, J. R.; Halse, M. E.; Blackledge, M.; Emsley, L. Direct Observation of Hierarchical Protein Dynamics. $\begin{array}{llll}\text { Science 2015, } & 348 \quad \text { (6234), } & \text { 578-581. }\end{array}$ https://doi.org/10.1126/science.aaa6111.

Schanda, P.; Ernst, M. Studying Dynamics by Magic-Angle Spinning Solid-State NMR Spectroscopy: Principles and Applications to Biomolecules. Prog Nucl Magn Reson Spectrosc 2016, $\quad 96, \quad 1-46$. https://doi.org/10.1016/j.pnmrs.2016.02.oo1.

Giraud, N.; Blackledge, M.; Goldman, M.; Böckmann, A.; Lesage, A.; Penin, F.; Emsley, L. Quantitative Analysis of Backbone Dynamics in a Crystalline Protein from Nitrogen15 Spin-Lattice Relaxation. J Am Chem Soc 2005, 127 (51), 18190-18201. https://doi.org/10.1021/jao55182h.

Ma, P.; Xue, Y.; Coquelle, N.; Haller, J. D.; Yuwen, T.; Ayala, I.; Mikhailovskii, O.; Willbold, D.; Colletier, J. P.; Skrynnikov, N. R.; Schanda, P. Observing the Overall Rocking Motion of a Protein in a Crystal. Nat Commun 2015, 6, 1-10. https://doi.org/10.1038/ncomms9361.

Kurauskas, V.; Izmailov, S. A.; Rogacheva, O. N.; Hessel, A.; Ayala, I.; Woodhouse, J.; Shilova, A.; Xue, Y.; Yuwen, T.; Coquelle, N.; Colletier, J.-P.; Skrynnikov, N. R.; Schanda, P. Slow Conformational Exchange and Overall Rocking Motion in Ubiquitin Protein Crystals. Nat Commun 2017, 8 (1), 145. https://doi.org/10.1038/s41467-017-00165-8.

Le Marchand, T.; De Rosa, M.; Salvi, N.; Sala, B. M.; Andreas, L. B.; Barbet-Massin, E.; Sormanni, P.; Barbiroli, A.; Porcari, R.; Sousa Mota, C.; De Sanctis, D.; Bolognesi, M.; Emsley, L.; Bellotti, V.; Blackledge, M.; Camilloni, C.; Pintacuda, G.; Ricagno, S. Conformational Dynamics in Crystals Reveal the Molecular Bases for D76N Beta-2 Microglobulin Aggregation Propensity. Nat Commun 2018, 9 (1), 1-11. https://doi.org/10.1038/s41467-018-04078-y.

Rovó, P.; Smith, C. A.; Gauto, D.; De Groot, B. L.; Schanda, P.; Linser, R. Mechanistic Insights into Microsecond TimeScale Motion of Solid Proteins Using Complementary $15 \mathrm{~N}$ and $1 \mathrm{H}$ Relaxation Dispersion Techniques. J Am Chem Soc 2019, 141 (2), 858-869. https://doi.org/10.1021/jacs.8bo9258. Singh, H.; Vasa, S. K.; Jangra, H.; Rovó, P.; Päslack, C.; Das, C. K.; Zipse, H.; Schäfer, L. V.; Linser, R. Fast Microsecond Dynamics of the Protein-Water Network in the Active Site of Human Carbonic Anhydrase II Studied by Solid-State NMR Spectroscopy. J Am Chem Soc 2019, 141 (49), 1927619288. https://doi.org/10.1021/jacs.9bo5311.

Agarwal, V.; Xue, Y.; Reif, B.; Skrynnikov, N. R. Protein Side-Chain Dynamics As Observed by Solution- and SolidState NMR Spectroscopy: A Similarity Revealed. J Am Chem Soc 2008, 130 (49), 16611-16621. https://doi.org/10.1021/ja804275p.

Mollica, L.; Baias, M.; Lewandowski, J. R.; Wylie, B. J.; Sperling, L. J.; Rienstra, C. M.; Emsley, L.; Blackledge, M. Atomic-Resolution Structural Dynamics in Crystalline Proteins from NMR and Molecular Simulation. J Phys Chem Lett 2012, 3 (23), 3657-3662. https://doi.org/10.1021/jz30162333. Lewandowski, J. R.; Sein, J.; Blackledge, M.; Emsley, L. 
Anisotropic Collective Motion Contributes to Nuclear Spin Relaxation in Crystalline Proteins. J Am Chem Soc 2010, 132 (4), 1246-1248. https://doi.org/10.1021/ja907067j.

(25) Ma, P.; Haller, J. D.; Zajakala, J.; Macek, P.; Sivertsen, A. C.; Willbold, D.; Boisbouvier, J.; Schanda, P. Probing Transient Conformational States of Proteins by Solid-State R $1 \rho$ Relaxation-Dispersion NMR Spectroscopy. Angew Chemie Int Ed 2014, 53 (17), 4312-4317. https://doi.org/10.1002/anie.201311275.

(26) Haller, J. D.; Schanda, P. Amplitudes and Time Scales of Picosecond-to-Microsecond Motion in Proteins Studied by Solid-State NMR: A Critical Evaluation of Experimental Approaches and Application to Crystalline Ubiquitin. $J$ Biomol NMR 2013, $57 \quad$ (3), 263-280. https://doi.org/10.1007/s10858-013-9787-x.

(27) Lamley, J. M.; Öster, C.; Stevens, R. A. R. A.; Lewandowski, J. R. Intermolecular Interactions and Protein Dynamics by Solid-State NMR Spectroscopy. Angew Chemie Int Ed 2015, 54 (51), 15374-15378. https://doi.org/10.1002/anie.201509168.

(28) Ferraroni, M.; Rypniewski, W.; Wilson, K. S.; Viezzoli, M. S.; Banci, L.; Bertini, I.; Mangani, S. The Crystal Structure of the Monomeric Human SOD Mutant $\mathrm{F}_{50} \mathrm{OE}_{\mathrm{G}} \mathrm{G}_{51} \mathrm{E} / \mathrm{E}_{133} \mathrm{Q}$ at Atomic Resolution. The Enzyme Mechanism Revisited. J $\begin{array}{lllll}M o l & \text { Biol 1999, } 288 & \text { (3), 413-426. }\end{array}$ https://doi.org/10.1006/jmbi.1999.2681.

(29) Tainer, J. A.; Getzoff, E. D.; Beem, K. M.; Richardson, J. S.; Richardson, D. C. Determination and Analysis of the $2 \AA$ Structure of Copper, Zinc Superoxide Dismutase. J Mol Biol 1982, 160 (2), 181-217. https://doi.org/10.1016/00222836(82)90174-7.

(30) Valentine, J. S.; Doucette, P. A.; Zittin Potter, S. CopperZinc Superoxide Dismutase and Amyotrophic Lateral Sclerosis. Annu Rev Biochem 2005, 74 (1), 563-593. https://doi.org/10.1146/annurev.biochem.72.121801.161647.

(31) Banci, L.; Bertini, I.; Cramaro, F.; Del Conte, R.; Rosato, A.; Viezzoli, M. S. Backbone Dynamics of Human $\mathrm{Cu}, \mathrm{Zn}$ Superoxide Dismutase and of Its Monomeric F5oE/G51E/E133Q Mutant: The Influence of Dimerization on Mobility and Function. Biochemistry 20oo, 39 (31), 91089118. https://doi.org/10.1021/bioooo67z.

(32) Hörnberg, A.; Logan, D. T.; Marklund, S. L.; Oliveberg, M. The Coupling between Disulphide Status, Metallation and Dimer Interface Strength in $\mathrm{Cu} / \mathrm{Zn}$ Superoxide Dismutase. J Mol Biol 2007, $365 \quad$ (2), $\quad 333-342$. https://doi.org/10.1016/j.jmb.2006.09.048.

(33) Banci, L.; Bertini, I.; Cantini, F.; D’Onofrio, M.; Viezzoli, M. S. Structure and Dynamics of Copper-Free SOD: The Protein before Binding Copper. Protein Sci 20o2, 11 (10), 2479-2492. https://doi.org/10.1110/ps.0210802.

(34) Fisher, C. L.; Cabelli, D. E.; Tainer, J. A.; Hallewell, R. A.; Getzoff, E. D. The Role of Arginine 143 in the Electrostatics and Mechanism of $\mathrm{Cu}, \mathrm{Zn}$ Superoxide Dismutase: Computational and Experimental Evaluation by Mutational Analysis. Proteins 1994, 19 (1), 24-34. https://doi.org/10.1002/prot.340190105.

（35） Banci, L.; Bertini, I.; Cramaro, F.; Del Conte, R.; Viezzoli, M. S. The Solution Structure of Reduced Dimeric Copper Zinc Superoxide Dismutase: The Structural Effects of Dimerization. Eur J Biochem 2002, 269 (7), 1905-1915. https://doi.org/10.1046/j.1432-1327.2002.02840.x.

(36) Banci, L.; Bertini, I.; Cramaro, F.; Del Conte, R.; Viezzoli, M. S. Solution Structure of Apo Cu, Zn Superoxide Dismutase: Role of Metal Ions in Protein Folding. Biochemistry 2003, 42 (32), 9543-9553. https://doi.org/10.1021/bio34324m.

(37) Shipp, E. L.; Cantini, F.; Bertini, I.; Valentine, J. S.; Banci, L. Dynamic Properties of the G93A Mutant of Copper-Zinc Superoxide Dismutase as Detected by NMR Spectroscopy: Implications for the Pathology of Familial Amyotrophic Lateral Sclerosis. Biochemistry 2003, 42 (7), 1890-1899. https://doi.org/10.1021/bio26704y.

(38) Banci, L.; Bertini, I.; Cantini, F.; D’Amelio, N.; Gaggelli, E.
Human SOD1 before Harboring the Catalytic Metal: Solution Structure of Copper-Depleted, Disulfide-Reduced Form. J Biol Chem 2006, 281 (4), 2333-2337. https://doi.org/10.1074/jbc.M506497200.

(39) Luchinat, E.; Banci, L. In-Cell NMR in Human Cells: Direct Protein Expression Allows Structural Studies of Protein Folding and Maturation. Acc Chem Res 2018, 51 (6), 15501557. https://doi.org/10.1021/acs.accounts.8boo147.

(40) Strange, R. W.; Antonyuk, S.; Hough, M. A.; Doucette, P. A.; Rodriguez, J. A.; Hart, P. J.; Hayward, L. J.; Valentine, J. S.; Hasnain, S. S. The Structure of Holo and Metal-Deficient Wild-Type Human $\mathrm{Cu}$, Zn Superoxide Dismutase and Its Relevance to Familial Amyotrophic Lateral Sclerosis. J Mol Biol 2003, 328 (4), 877-891. https://doi.org/10.1016/Soo222836(03)00355-3.

(41) Banci, L.; Bertini, I.; Cramaro, F.; Del Conte, R.; Viezzoli, M. S. The Solution Structure of Reduced Dimeric Copper Zinc Superoxide Dismutase: The Structural Effects of Dimerization. Eur J Biochem 2002, 269 (7), 1905-1915. https://doi.org/10.1046/j.1432-1033.2002.02840.x.

(42) Knight, M. J.; Webber, A. L.; Pell, A. J.; Guerry, P.; BarbetMassin, E.; Bertini, I.; Felli, I. C.; Gonnelli, L.; Pierattelli, R.; Emsley, L.; Lesage, A.; Herrmann, T.; Pintacuda, G. Fast Resonance Assignment and Fold Determination of Human Superoxide Dismutase by High-Resolution Proton-Detected Solid-State MAS NMR Spectroscopy. Angew Chemie Int Ed 2011, $50 \quad$ (49), 11697-11701. https://doi.org/10.1002/anie.201106340.

(43) Knight, M. J.; Pintacuda, G. Paramagnetic Systems in Biochemistry: Solid-State NMR Studies. Encycl Magn Reson 2012, 11 (3), 645-652. https://doi.org/10.1002/9780470034590.emrstm1072.

(44) Krushelnitsky, A.; Zinkevich, T.; Reichert, D.; Chevelkov, V.; Reif, B. Microsecond Time Scale Mobility in a Solid Protein as Studied by the ${ }_{15} \mathrm{~N}$ Ri $\rho$ Site-Specific NMR Relaxation Rates. J Am Chem Soc 2010, 132 (34), 11850-11853. https://doi.org/10.1021/ja103582n.

(45) Lewandowski, J. R.; Sass, H. J.; Grzesiek, S.; Blackledge, M.; Emsley, L. Site-Specific Measurement of Slow Motions in Proteins. J Am Chem Soc 2011, 133 (42), 16762-16765. https://doi.org/10.1021/ja206815h.

(46) Smith, A. A.; Ernst, M.; Meier, B. H. Because the Light Is Better Here: Correlation-Time Analysis by NMR Spectroscopy. Angew Chemie Int Ed 2017, 56 (44), 1359013595. https://doi.org/10.1002/anie.201707316.

(47) Strange, R. W.; Antonyuk, S. V.; Hough, M. A.; Doucette, P. A.; Valentine, J. S.; Hasnain, S. S. Variable Metallation of Human Superoxide Dismutase: Atomic Resolution Crystal Structures of $\mathrm{Cu}-\mathrm{Zn}, \mathrm{Zn}-\mathrm{Zn}$ and as-Isolated Wild-Type Enzymes. J Mol Biol 2006, 356 (5), 1152-1162. https://doi.org/10.1016/j.jmb.2005.11.081.

(48) Banci, L.; Bertini, I.; Cantini, F.; D’Onofrio, M.; Viezzoli, M. S. Structure and Dynamics of Copper-Free SOD: The Protein before Binding Copper. Protein Sci 2009, 11 (10), 2479-2492. https://doi.org/10.1110/ps.0210802.

(49) Sheng, Y.; Capri, J.; Waring, A.; Valentine, J. S.; Whitelegge, J. Exposure of Solvent-Inaccessible Regions in the Amyloidogenic Protein Human SOD1 Determined by Hydroxyl Radical Footprinting. J Am Soc Mass Spectrom 2019, 30 (2), 218-226. https://doi.org/10.1007/s13361-0182075-y.

(50) Ding, F.; Dokholyan, N. V. Dynamical Roles of Metal Ions and the Disulfide Bond in $\mathrm{Cu}$, Zn Superoxide Dismutase Folding and Aggregation. Proc Natl Acad Sci USA 2008, 105 (50), 19696-19701. https://doi.org/10.1073/pnas.0803266105.

(51) Antonyuk, S.; Elam, J. S.; Hough, M. A.; Strange, R. W.; Doucette, P. A.; Rodriguez, J. A.; Hayward, L. J.; Valentine, J. S.; Hart, P. J.; Hasnain, S. S. Structural Consequences of the Familial Amyotrophic Lateral Sclerosis SOD1 Mutant His46Arg. Protein Sci 2005, 14 (5), 1201-1213. https://doi.org/10.1110/ps.041256705. 
(52) Henzler-Wildman, K. A.; Lei, M.; Thai, V.; Kerns, S. J.; Karplus, M.; Kern, D. A Hierarchy of Timescales in Protein Dynamics Is Linked to Enzyme Catalysis. Nature 2007, 450 (7171), 913-916. https://doi.org/10.1038/natureo6407.

(53) Culik, R. M.; Sekhar, A.; Nagesh, J.; Deol, H.; Rumfeldt, J. A. O.; Meiering, E. M.; Kay, L. E. Effects of Maturation on the Conformational Free-Energy Landscape of SOD1. Proc Natl Acad Sci USA 2018, 115 (11), E2546-E2555. https://doi.org/10.1073/pnas.1721022115.

(54) Li, S.; Hong, M. Protonation, Tautomerization, and Rotameric Structure of Histidine: A Comprehensive Study by Magic-Angle-Spinning Solid-State NMR. J Am Chem Soc 2011, 133 (5), 1534-1544. https://doi.org/10.1021/ja108943n.

(55) Klug, D.; Fridovic.I; Rabani, J. Direct Demonstration of Catalytic Action of Superoxide Dismutase through Use of Pulse Radiolysis. J Biol Chem 1972, 247 (15), 4839-.

(56) Good, D. B.; Wang, S.; Ward, M. E.; Struppe, J.; Brown, L. S.; Lewandowski, J. R.; Ladizhansky, V. Conformational Dynamics of a Seven Transmembrane Helical Protein Anabaena Sensory Rhodopsin Probed by Solid-State NMR. J Am Chem Soc 2014, 136 (7), 2833-2842. https://doi.org/10.1021/ja411633w.

(57) Gauto, D. F.; Hessel, A.; Rovó, P.; Kurauskas, V.; Linser, R.; Schanda, P. Protein Conformational Dynamics Studied by $15 \mathrm{~N}$ and 1 H R $1 \rho$ Relaxation Dispersion: Application to Wild-Type and G53A Ubiquitin Crystals. Solid State Nucl Magn Reson 2017, 87 (January), 86-95. https://doi.org/10.1016/j.ssnmr.2017.04.002.

(58) Furukawa, Y.; O'Halloran, T. V. Amyotrophic Lateral Sclerosis Mutations Have the Greatest Destabilizing Effect on the Apo- and Reduced Form of SOD1, Leading to Unfolding and Oxidative Aggregation. J Biol Chem 2005, 280 (17), 17266-17274.
(59) Rodriguez, J. A.; Valentine, J. S.; Eggers, D. K.; Roe, J. A.; Tiwari, A.; Brown, R. H.; Hayward, L. J. Familial Amyotrophic Lateral Sclerosis-Associated Mutations Decrease the Thermal Stability of Distinctly Metallated Species of Human Copper/Zinc Superoxide Dismutase. J Biol Chem 2002, 277 (18), 15932-15937. https://doi.org/10.1074/jbc.M11208820o.

(6o) Wang, J.; Caruano-Yzermans, A.; Rodriguez, A.; Scheurmann, J. P.; Slunt, H. H.; Cao, X.; Gitlin, J.; Hart, P. J.; Borchelt, D. R. Disease-Associated Mutations at Copper Ligand Histidine Residues of Superoxide Dismutase 1 Diminish the Binding of Copper and Compromise Dimer Stability. J Biol Chem 2007, 282 (1), 345-352. https://doi.org/10.1074/jbc.M604503200.

(61) Tollinger, M.; Sivertsen, A. C.; Meier, B. H.; Ernst, M.; Schanda, P. Site-Resolved Measurement of Microsecond-toMillisecond Conformational-Exchange Processes in Proteins by Solid-State NMR Spectroscopy. J Am Chem Soc 2012, $134 \quad$ (36), 14800-14807. https://doi.org/10.1021/jazo3591y.

(62) Ban, D.; Gossert, A. D.; Giller, K.; Becker, S.; Griesinger, C.; Lee, D. Exceeding the Limit of Dynamics Studies on Biomolecules Using High Spin-Lock Field Strengths with a Cryogenically Cooled Probehead. J Magn Reson 2012, 221, 14. https://doi.org/10.1016/j.jmr.2012.05.005.

(63) Khare, S. D.; Dokholyan, N. V. Common Dynamical Signatures of Familial Amyotrophic Lateral SclerosisAssociated Structurally Diverse $\mathrm{Cu}, \mathrm{Zn}$ Superoxide Dismutase Mutants. Proc Natl Acad Sci USA 20o6, 103 (9), 3147-3152. https://doi.org/10.1073/pnas.0511266103.

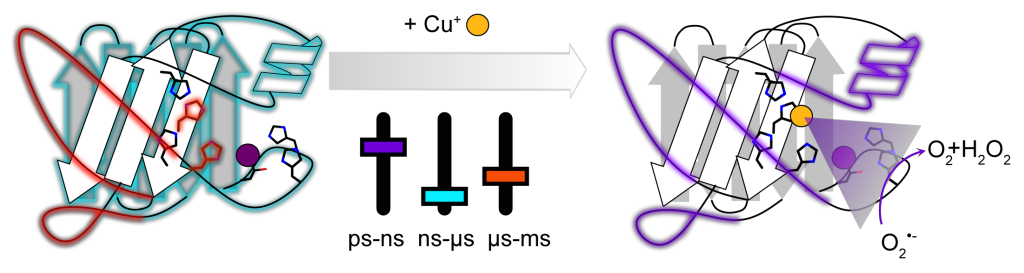

